Research Article

\title{
Chemically Defined Conditions Mediate an Efficient Induction of Dental Pulp Pluripotent-Like Stem Cells into Hepatocyte- Like Cells
}

\author{
Carlos Gil-Recio, ${ }^{1}$ Sheyla Montori, ${ }^{1}$ Saddam Al Demour, ${ }^{2}$ Mera A. Ababneh, ${ }^{3}$ \\ Eduard Ferrés-Padró, ${ }^{4}$ Carles Marti, ${ }^{5}$ Elvira Ferrés-Amat, ${ }^{6}$ Miguel Barajas, ${ }^{7}$ \\ Ashraf Al Madhoun $\mathbb{D D}^{8}$ and Maher Atari $\mathbb{D}^{1,9}$ \\ ${ }^{1}$ Regenerative Medicine Research Institute, UIC Barcelona, Barcelona, Spain \\ ${ }^{2}$ Department of Special Surgery/Division of Urology, The University of Jordan, School of Medicine, Amman, Jordan \\ ${ }^{3}$ Department of Clinical Pharmacy, Faculty of Pharmacy, Jordan University of Science and Technology, Amman, Jordan \\ ${ }^{4}$ Oral and Maxillofacial Surgery Department, Fundació Hospital de Nens de Barcelona, Barcelona, Spain \\ ${ }^{5}$ Oral and Maxillofacial Surgery Department, Hospital Clinico de Barcelona, Barcelona, Spain \\ ${ }^{6}$ Pediatric Dentistry Service, Oral and Maxillofacial Surgery Service, Hospital de Nens de Barcelona, Barcelona, Spain \\ ${ }^{7}$ Biochemistry and Molecular Biology Department, Universidad Pública de Navarra, Pamplona, Spain \\ ${ }^{8}$ Department of Genetics and Bioinformatics, Functional Genomic Unit, Dasman Diabetes Institute, Kuwait \\ ${ }^{9}$ Biointelligent Technology Systems SL, Diputaccion 316, 3D, 08009 Barcelona, Spain
}

Correspondence should be addressed to Ashraf Al Madhoun; ashraf.madhoun@dasmaninstitute.org and Maher Atari; matari@biointelligentsl.com

Received 15 August 2021; Revised 15 October 2021; Accepted 18 October 2021; Published 8 November 2021

Academic Editor: Jun Liu

Copyright (c) 2021 Carlos Gil-Recio et al. This is an open access article distributed under the Creative Commons Attribution License, which permits unrestricted use, distribution, and reproduction in any medium, provided the original work is properly cited.

\begin{abstract}
Liver diseases are major causes of morbidity and mortality. Dental pulp pluripotent-like stem cells (DPPSCs) are of a considerable promise in tissue engineering and regenerative medicine as a new source of tissue-specific cells; therefore, this study is aimed at demonstrating their ability to generate functional hepatocyte-like cells in vitro. Cells were differentiated on a collagen scaffold in serum-free media supplemented with growth factors and cytokines to recapitulate liver development. At day 5 , the differentiated DPPSC cells expressed the endodermal markers FOXA1 and FOXA2. Then, the cells were derived into the hepatic lineage generating hepatocyte-like cells. In addition to the associated morphological changes, the cells expressed the hepatic genes HNF6 and AFP. The terminally differentiated hepatocyte-like cells expressed the liver functional proteins albumin and CYP3A4. In this study, we report an efficient serum-free protocol to differentiate DPPSCs into functional hepatocyte-like cells. Our approach promotes the use of DPPSCs as a new source of adult stem cells for prospective use in liver regenerative medicine.
\end{abstract}

\section{Introduction}

The liver is the largest internal organ providing essential metabolic, exocrine, and endocrine metabolites. Hepatocytes and cholangiocytes, the bile duct epithelial cells, are parenchymal cells which comprise approximately $70 \%$ of the adult liver mass. Both cell types are derived from the embryonic definitive endoderm [1]. The liver is the main body homeostasis regulator; therefore, liver diseases cause high morbidity and mortality rates. The incidence of endstage liver disease (ESLD) is increasing worldwide due to alcohol-induced liver disease, nonalcoholic fatty liver disease, or hepatitis [2]. Orthotopic liver transplantation (OLT) is the current optimal treatment with more than $70 \%$ of the overall 5 -year survival rate for certain ESLD cases [3]. OLT obstacles include donor availability, surgical risk, high costs, and the requirement for lifelong immunosuppressors $[4,5,6]$. Alternatively, hepatocyte transplantation (HT) is a promising 
procedure, less invasive, can be performed repeatedly, and mainly used to replace an inborn-deficient metabolic function $[7,8]$. Yet, HT hurtles include donor availability, low cell engraftment, and longevity [9]. Therefore, the scientific community has put an effort to improve cell-based hepatocyte generation.

Dental pulp stem cells (DPSCs) are multipotent heterogeneous cell population embedded within the pulp cavity of impacted adult third molars. DPSCs were initially isolated and characterized by Gronthos et al. [10]. Subsequently, several investigators reported DPSCs' isolation, characterization, differentiation, and banking $[11,12]$. In comparison with embryonic and other adult stem cells, DPSCs are obtained from disposable dental pulp after occlusion management, which is considered as a medical waste, noninvasive isolation procedure, absence of ethical constraints, and no risk of teratoma formation. Furthermore, DPSCs do not compromise their stemness, viability, proliferation, or differentiating capabilities after cryopreservation [13, 14]. Therefore, DPSCs have the potential to be a promising personalized patient-specific stem cell source for regenerative therapy. Nevertheless, a major concern is that DPSCs comprise progenitor cell populations that are marked by diverse characteristics, such as clonal heterogeneity, multilineage differentiation, self-renewal capacity, and phenotypic complexity.

In the context of cell-based hepatogenesis, DPSCmediated hepatocyte-like generation has advanced rapidly because of the previously accumulated differentiation protocols applied for human embryonic stem cells (hESCs) and bone marrow mesenchymal cells (BM-MSCs) as prospective sources for regenerative hepatocytes [15-20]. Implementing defined, serum-free, and stepwise differentiation protocols that mimic hepatocytes' developmental stages during embryogenesis is sufficient for inducing hepatogenesis. Using this approach, Ishkitiev et al. were the pioneers to demonstrate the hepatogenic differentiation potential of DPSCs. Initially, Ishkitiev et al. developed two staged conditioned media containing a low percentage of fetal bovine serum (FBS) but enriched with essential hepatogenic inducers [21]. Later, they used serum-free conditioned media to generate hepatocyte-like cells from CD $117^{+}$DPSC subpopulation [22]. The latter hepatogenesis protocol utilized three developmental stages, i.e., cell specification, differentiation, and maturation, to generate cells with morphological, phenotypical, and functional characteristics like hepatocytes. This approach was further improved and implemented in later studies [11, 23]. Nevertheless, the heterogeneity nature of the DPSCs influences their differentiation capacity and yield; therefore, we focused our efforts to identify and characterize the differentiation potential of a defined subpopulation of DPSCs with pluripotent-like phenotype [24-28].

Dental pulp pluripotent stem cells (DPPSCs) are a unique subpopulation of DPSCs [25], expressing the pluripotency markers Oct4A, NANOG, and SOX2 [24, 29, 30]. DPPSCs exhibit normal human karyotype with no aneuploidy, polyploidy, or any chromosomal abnormality during the metaphase stage even after more than 65 passages [24, 31]. Unlike other adult stem cells, DPPSCs form teratoma- like structures when injected subcutaneously in immunodeficient mice and generate embryonic bodies like in in vitro cultures, which are exclusive phenotypes of hESCs and induced pluripotent stem cells (iPSCs) [24, 32-34]. Furthermore, DPPSCs can be differentiated into cells from each of the three embryonic germ layers, including osteocytes and chondrocytes [25, 26], endothelial- and neural-like cells $[25,26]$, and smooth and skeletal muscles [27].

In this study, we evaluated the adult DPPSC-mediated hepatogenic capacity using a novel serum free-directed stepwise differentiation protocol and collagen scaffolds to induce 3-dimensional (3D) culture conditions. DPPSCs were first differentiated into definitive endoderm (DE), which was progressively directed to the hepatogenic lineage. We observed that treatment of DPPSCs, seeded on scaffolds, with activin A (Act A), Wnt family member 3A (Wnt3A), and knockout serum replacement (KOSR) conditioned media, enhances their commitment capacity toward DE lineage. Subsequently, treatment with fibroblast growth factor 4 (FGF4) and hepatocyte growth factor (HGF) induced gut tube formation, early hepatogenic markers. Finally, functional hepatocyte-like cells were generated in conditional differentiation medium supplemented with HGF, FGF4, dexamethasone (Dex), and oncostatin M (OSM). Preliminary results were previously published in a preprint [35].

\section{Materials and Methods}

2.1. Ethical Approval and Statement. All the research in the present study was conducted in accordance with the code of ethics of the World Medical Association for experiments involving humans (Helsinki Declaration of 1975) and the Guidelines for Human Stem Cell Research issued by the Committee of Bioethics at the Universitat Internacional de Catalunya, Spain.

2.2. DPPSC Culture and Maintenance. DPPSC clones were previously isolated and characterized by our group as previously described [24, 31]. Supplementary Figures $1 \mathrm{~A}$ and 1C show morphological differences between DPSC and DPPSCs, respectively. In brief, immediately after extraction, the third molars were vigorously washed with $70 \%$ ethanol and sterile distilled water. The molar pulp tissues were extracted, and cells were isolated by digesting the pulp tissue with collagenase type I ( $3 \mathrm{mg} / \mathrm{ml}$, Sigma-Aldrich, Germany) for 60 minutes at $37^{\circ} \mathrm{C}$. Then, cells were separated mechanically with an insulin syringe and centrifuged for 10 minutes at $1800 \mathrm{rpm}$. Primary cell lines were established, the medium was changed every 4 days, and cell density was maintained at a low density of $80-100$ cells $/ \mathrm{cm}^{2}$. DPPSCs were cultured in precoated flasks with $100 \mathrm{ng} / \mathrm{ml}$ fibronectin (Life Technologies, Waltham, MA, USA) in a medium consisting of $60 \%$ DMEM-low glucose (Life Technologies) and 40\% MCDB-201 (Sigma-Aldrich), supplemented with $1 \times$ SITE Liquid Media Supplement (Sigma-Aldrich), $1 \times$ linoleic acid-bovine serum albumin (LA-BSA, SigmaAldrich), $10^{-4} \mathrm{M}$ L-ascorbic acid 2-phosphate (SigmaAldrich), $1 \times$ penicillin-streptomycin (Life Technologies), 2\% fetal bovine serum (FBS, Sigma-Aldrich), $10 \mathrm{ng} / \mathrm{ml}$ hPDGF- 
BB (Abcam, Waltham, MA, USA), 10 ng/ml EGF (SigmaAldrich), $1000 \mathrm{U} / \mathrm{ml}$ LIF (Millipore, USA), chemically defined lipid concentrate (Life Technologies), $0.8 \mathrm{mg} / \mathrm{ml} \mathrm{BSA}$ (Sigma-Aldrich), and $55 \mu \mathrm{M} \beta$-mercaptoethanol (SigmaAldrich).

\subsection{Definitive Endoderm Induction Using Growth Factors.} For the DE induction, $5 \times 10^{4} \mathrm{cells} / \mathrm{cm}^{2}$ were seeded on 6well plates (Cellcoat, UK) and cultured in RPMI medium (Mediatech, Los Altos, CA, USA) containing GlutaMAX (Life Technologies), penicillin/streptomycin, and 0.5\% defined fetal bovine serum (FBS, HyClone, Cytiva Europe $\mathrm{GmbH}$, Spain) and supplemented with each one of the following combinations of growth factors: (i) $100 \mathrm{ng} / \mathrm{ml}$ Act A (R\&D Systems, UK), (ii) $100 \mathrm{ng} / \mathrm{ml}$ Act A+50 ng/ml Wnt3A (R\&D Systems), (iii) $100 \mathrm{ng} / \mathrm{ml}$ Act $\mathrm{A}+50 \mathrm{ng} / \mathrm{ml}$ bone morphogenetic protein-4 (BMP4, R\&D Systems), (iv) $100 \mathrm{ng} / \mathrm{ml}$ Act A+50 ng $/ \mathrm{ml} \mathrm{Wnt} 3 \mathrm{~A}+50 \mathrm{ng} / \mathrm{ml} \mathrm{BMP} 4$, (v) $100 \mathrm{ng} / \mathrm{ml} \mathrm{Act}$ A $+10 \mathrm{ng} / \mathrm{ml} \mathrm{FGF4} \mathrm{(R \& D} \mathrm{Systems),} \mathrm{or} \mathrm{(vi)} 100 \mathrm{ng} / \mathrm{ml}$ Act A $+10 \mathrm{ng} / \mathrm{ml}$ basic-FGF (bFGF, Life Technologies). Three days after induction, the medium was changed to the same RPMI-based medium and supplements except for the replacement of FBS with 2\% KOSR (Life Technologies) and the incubation was maintained for another 2 days.

\subsection{Definitive Endoderm Induction Using Different} Biomaterials. Application of biomaterials to cell culture has been shown to enhance cellular programming and differentiation. In this study, we used collagen I or fibronectin, the most abundant components of the extracellular matrix that provide structural networks for the cells microenvironment and were reported to enhance $\mathrm{DE}$ differentiation in vitro $[36,37]$. Using the sample induction media described above, cells were seeded on plates coated with collagen type I, $100 \mathrm{ng} / \mathrm{ml}$ fibronectin, or were cocultured with HepG2 cells $\left(20,000 \mathrm{cell} / \mathrm{cm}^{2}\right)$, in addition to the controls.

2.5. Hepatogenic Differentiation. After setting the optimal conditions for DE induction, we aimed to generate stepwise functional hepatocyte-like cell. The gut tube and hepatocyte specifications were initiated using RPMI medium supplemented with $2 \% \mathrm{KOSR}, 10 \mathrm{ng} / \mathrm{ml} \mathrm{FGF} 4$, and $10 \mathrm{ng} / \mathrm{ml}$ HGF (R\&D Systems). Three days later, RPMI was replaced with the enriched minimum essential medium (MEM, SigmaAldrich) supplemented with $1 \%$ BSA, $10 \mathrm{ng} / \mathrm{ml} \mathrm{FGF4,} \mathrm{and}$ $10 \mathrm{ng} / \mathrm{ml} \mathrm{HGF}$. Three days later, hepatocyte maturation was induced using complete hepatocyte culture medium (HCM, SingleQuots, Lonza, USA) with all supplements according to the manufacturer's recommendations, containing $10 \mathrm{ng} / \mathrm{ml}$ FGF4, $10 \mathrm{ng} / \mathrm{ml} \mathrm{HGF,} 10 \mathrm{ng} / \mathrm{ml} \mathrm{OSM}$, and $10^{-7} \mathrm{M}$ Dex (Sigma-Aldrich). The hepatocyte maturation was proceeded for nine days as previously reported by Ishkitiev et al. [21, $22]$. The differentiation protocol was performed for a total of 22 days, and the media were refreshed every 2-3 days.

2.6. Immunofluorescence Microscope Imaging. Immunofluorescence was performed as described previously [38, 39]. Briefly, cells were cultured overnight on glass coverslips coated with collagen I, fixed with $4 \%$ paraformaldehyde for $15 \mathrm{~min}$, and permeabilized with $10 \%$ Triton X-100 for
30 min. Then, cells were blocked with 5\% BSA in PBS for $30 \mathrm{~min}$ and incubated for one hour with the primary antibodies: alpha-1 antitrypsin (AAT, Abcam) or albumin (Alb, Abcam) followed by a one-hour incubation with prospective secondary antibodies (Abcam). Between each step, cells were washed with $1 \%$ BSA in PBS. Fluorescent images were captured using a fluorescence microscopy Olympus AX70 (Olympus Optical, Tokyo, Japan) as previously described $[40,41]$.

2.7. Immunocytochemistry. Cells were fixed with ThinPrep CytoLyt solution for $30 \mathrm{~min}$ at room temperature and centrifuged at 5,000 rpm for $5 \mathrm{~min}$. Cell's pellet was solubilized in ThinPrep CytoLyt solution and then resuspended in PreservCyt solution (ThinPrep) for $15 \mathrm{~min}$ and processed on a ThinPrep 2000 processor. The microscope slides harboring the processed cells were fixed with $96 \%$ ethanol, washed twice with distilled water, and blocked in $0.5 \%$ hydrogen peroxide/methanol for $10 \mathrm{~min}$. Immunostainings were performed using a Leica Bond-MAX automated IHC and ISH Stainer in accordance with the manufacturer's instructions. Briefly, the slides were washed with bond wash solution (Biosystems, USA) and the antigens retrieval procedure was performed in accordance with bond heat standard protocol (ER1) using citric buffer, $\mathrm{pH} 6$, for $30 \mathrm{~min}$ at $95^{\circ} \mathrm{C}$. Slides were washed and treated with postprimary solution for $8 \mathrm{~min}$. Next, the slides were incubated in alkaline phosphatase (AP)-Polymer for $8 \mathrm{~min}$ and washed. Then, the mixed diaminobenzidine refine solution was applied for $10 \mathrm{~min}$. Samples were counterstained with water hematoxylin for $5 \mathrm{~min}$. Nonimmune immunoglobulins of the same isotype as the primary antibodies were used as a control for each experiment.

2.8. RNA Extraction, cDNA Synthesis, and $q R T-P C R$ Reactions. Total RNA was extracted from cells using the total RNA purification TRIzol Reagent (Life Technologies) in accordance with the manufacturer's protocol. RNA was quantified using a NanoDrop 2000c spectrophotometer (Thermo Fisher Scientific, Waltham, MA, USA), and RNA integrity was evaluated by $2 \%$ agarose gel electrophoresis [42]. First-strand cDNA was synthesized from $200 \mathrm{ng}$ RNA by reverse transcription using QuantiTect Reverse Transcription Kit (Qiagen Inc., Germantown, MD, USA). qRTPCR reactions were performed as previously described [43, 44]. Primer pairs with equivalent efficiencies (Table 1) were selected from PrimerBank [45] or designed using PrimerBLAST tools (http://www.ncbi.nlm.nih.gov/tools/primerblast/) [46]. qRT-PCR was performed on the ABI7900 system (Applied Biosystems, USA) using SDS software. Relative gene expression was calculated using a comparative Ct method as previously described [47, 48]. Results were normalized to GAPDH CT values, and the relative expressions determined relative to control or day 0 undifferentiated cells. Data show the means \pm standard deviation. Total liver RNA (Life Technologies) was used as a positive control.

2.9. Hepatic Biochemical Analysis of Supernatants. Hepatic enzymatic profiles for aspartate transaminase (AST), alanine 
TABLE 1: Oligonucleotide sequences of primers utilized for real-time qRT-PCR.

\begin{tabular}{lcc}
\hline Gene & Forward primer $\left(5^{\prime}-3^{\prime}\right)$ & Reverse $^{\prime}$ primer $\left(5^{\prime}-3^{\prime}\right)$ \\
\hline GAPDH & TGCACCACCAACTGCTTAGC & GGCATGGACTGTGGTCATGAG \\
FoxA1 & GCCTACTCCTCCGTCCCGGT & CCGGGGTCATGTTGCCGCTC \\
FoxA2 & GCGACCCCAAGACCTACAG & GGTTCTGCCGGTAGAAGGG \\
Gata4 & TCCCTCTTCCCTCCTCAAAT & TTCCCCTAACCAGATTGTCG \\
AFP & AGGGTGTAGCGCTGCAAACGA & TGTTCCTGGCCTTGGCAGCAT \\
Oct4A & GACAGGGGGAGGGGAGGAGCTAGG & CTTCCCTCCAACCAGTTGCCCCAAAC \\
HNF6 & CTTAGCAGCATGCAAAAGGA & TGCGTTCATGAAGAAGTTGC \\
CK19 & GAGGAAATCAGTACGCTGAG & GTTTCTGCCAGTGTGTCTTC \\
HNF4 $\alpha$ & ACTACATCAACGACCGCCAGT & ATCTGCTCGATCATCTGCCAG \\
Alb & CCTTGGTGTTGATTGCCTTTGCTC & CATCACATCAACCTCTGGTCTCACC \\
G6P & TCAGCTCAGGTGGTCCTCTT & CCTCCTTAGGCAGCCTTCTT \\
AAT & TCGCTACAGCCTTTGCAATG & TTGAGGGTACGGAGGAGTTCC \\
CYP7A1 & AGGACGGTTCCTACAACATC & CGATCCAAAGGGCATGTAGT \\
\hline
\end{tabular}

aminotransferase (ALT), alkaline phosphatase (ALP), and gamma-glutamyl transferase (GGT) were analyzed from supernatant extracts of the different samples. The activity was measured by specific colorimetric detection kit (Linear Chemicals, Spain) at $25^{\circ} \mathrm{C}$ in accordance with the manufacturer's instructions. The specific compounds used for the following kinetics of the reaction were as follows: for AST and ALT, the oxidation of NADH was measured at light absorbance at $340 \mathrm{~nm}$; for ALP, the formation of 4nitrophenol was measured at light absorbance at $405 \mathrm{~nm}$; for GGT, the catalysis of $\gamma$-glutamyl-3-carboxy-4-nitroanilide was measured at light absorbance at $410 \mathrm{~nm}$ using spectrophotometer (Thermo Fisher Scientific).

2.10. Cytochrome P450 3A4 Metabolic Activity Assay. Cytochrome P450 3A4 (CYP3A4) enzyme activity assays were assessed by measurement of luciferase activity using P450Glo CYP3A4 assay kit (Promega, Madison, WI, USA) in accordance with the manufacturer's instructions. Differentiated and undifferentiated control DPPSC cells were treated with $25 \mu \mathrm{M}$ rifampicin for $48 \mathrm{hrs}$. Then, treated cells were incubated with a fresh serum-free medium containing $50 \mu \mathrm{M}$ luciferin PFBE with or without $5 \mu \mathrm{M}$ erythromycin (an antagonist) for $30 \mathrm{~min}$ at $37^{\circ} \mathrm{C}$. Then, $50 \mu \mathrm{l}$ of the medium was transferred into a 96-well plate and mixed with $50 \mu \mathrm{l}$ luciferin detection reagent to initiate the luminescent reaction. After $20 \mathrm{~min}$ incubation at room temperature, the luminescence was measured with a luminometer (BioTek, USA).

2.11. Albumin Assay. Alb secretion was measured by using an Albumin Fluorescence Assay Kit (Fluka, USA) in accordance with the manufacturer's instructions. Briefly, a calibration curve was generated using the kit-supplied standard human Alb concentrations. These calibration samples were mixed with albumin Blue 580 reagent prediluted in buffer solution. The fluorescence was measured in a spectrophotometer (absorbance wavelength peal, $\lambda \mathrm{ex}=$ $600 \mathrm{~nm}$, and $\lambda \mathrm{em}=630 \mathrm{~nm}$ ). Differentiated and undifferen- tiated control DPPSCs were mixed with the same reagents, and the fluorescence was measured under the same conditions. Results are extrapolated to the calibration curve. Conditioned medium was collected from equivalent numbers of cells.

2.12. Periodic Acid-Schiff Staining for Glycogen Accumulation. At differentiation day 22, differentiated and undifferentiated control DPPSCs were fixed in $4 \%$ formaldehyde for $15 \mathrm{~min}$ at room temperature. After two washing steps with PBS, cells were incubated in $1 \%$ periodic acid for $5 \mathrm{~min}$ and then washed with distilled water. The treated cells were incubated with Schiff's reagent (Sigma-Aldrich) for $15 \mathrm{~min}$. After a $10 \mathrm{~min}$ wash in distilled water, hematoxylin counterstain solution was applied for $90 \mathrm{sec}$ and washed with distilled water.

2.13. Statistical Analysis. Results are reported as the mean \pm standard deviation (see figure legend for specific details regarding the number of biological replicates, independent experiments, and technical replicates). Statistics were performed using the Statgraphics XVI software. The methods used were two-tailed Student's $t$-test and ANOVA for multiple factors. Values with $p<0.05$ were considered statistically significant.

\section{Results}

3.1. Definitive Endoderm Induction. Using hESCs, iPSCs, and human umbilical cord Wharton's jelly mesenchymal stem cells, studies have shown that Act A is the main DE induction factor $[49,50,51,52]$. Therefore, we tested this concept on DPPSCs using Act A with or without other signaling factors to delineate the optimal conditional media sufficient to mediate DE differentiation. Quantitative realtime PCR (qRT-PCR) analyses demonstrated a differential induction of the DE genes Forkhead Boxes A1 and A2 (FoxA1 and FoxA2) at day 5. FoxA1 transcripts elevated significantly in conditional media supplemented with Act 


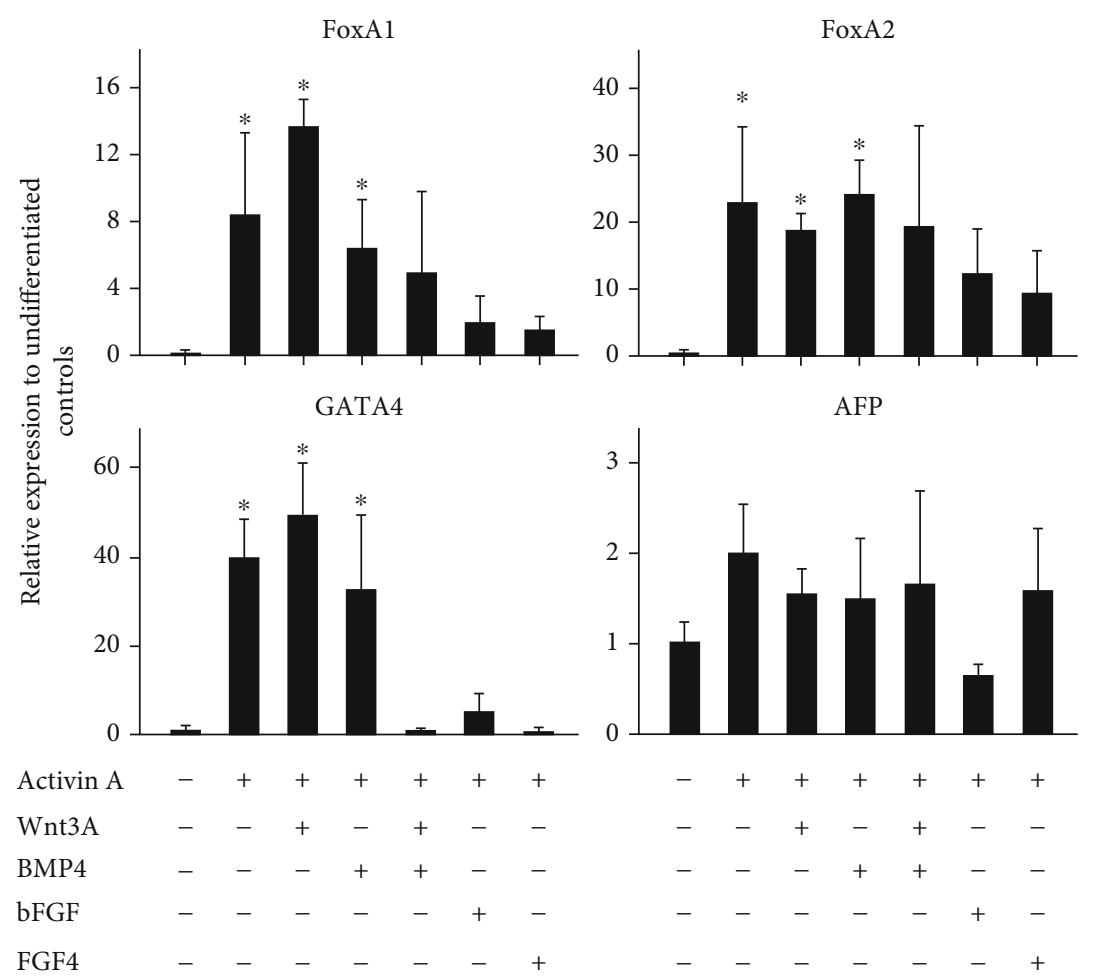

(a)

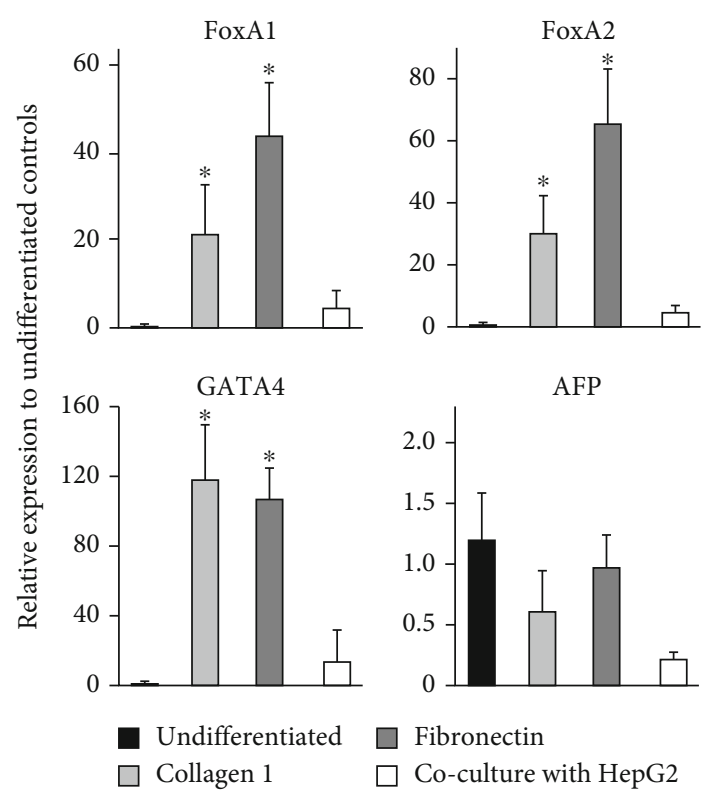

(b)

FIGURE 1: Molecular evaluation of different signaling factors and biomaterials on the generation of definitive endoderm lineage. qRT-PCR was performed for the indicated genes at day 5 of DPPSC differentiation into DE lineage. (a) Cells treated with differentiation conditional media supplemented with indicated signaling factors. (b) Cells were seeded on precoated plates with/without the described scaffolds or cocultured with HepG2 cells. Results were normalized to GAPDH and expressed relative to undifferentiated cells at day. Data are shown as the mean $\pm \mathrm{SD}(n=4) .{ }^{*} p<0.05$.

$A$ and Wnt3A, 14-fold relative to undifferentiated cells (Figure 1(a)). Similar induction levels were also observed in cells treated with Act A alone or Act A and BMP4, but albeit to a lower degree (6- to 8-fold) and notable variations between different experiments. Alternatively, FoxA2 expres- sion levels were comparable in all tested conditional media, with a statistically significant 20 -fold induction in media supplemented with Act A alone, and with Wnt3A or BMP4. Remarkably, conditional media supplemented with Act A and bFGF or FGF4 failed to significantly upregulate 
DPPSCs- mediated hepatogenesis

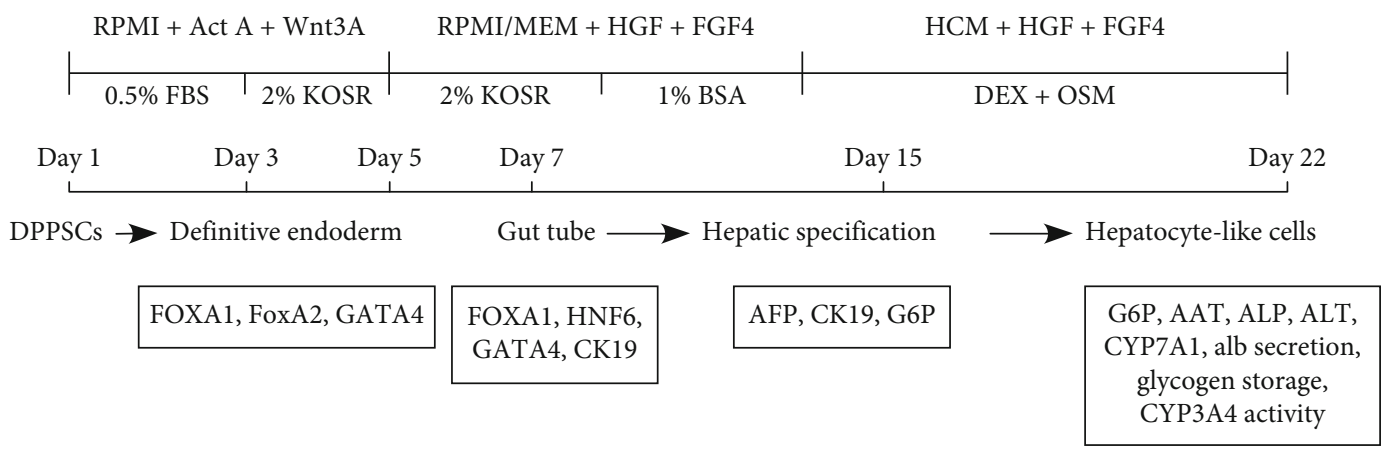

FIGURE 2: The experimental protocol for DPPSC-mediated hepatocyte-like cell generation. Schematic representation of the differentiation protocol including the key manipulated signaling pathways and the different molecular and functional studies performed.

the studied DE genes. Moreover, qRT-PCR analyses indicated an elevation in the transcript levels of GATA4, with a 40 to 60 -fold increase relative to undifferentiated cells, posttreatment with Act A alone or in the presence of Wnt3A or BMP4 (Figure 1(a)). In contrary, no GATA4 transcripts were detected in conditional media containing the three signaling factors together (Figure 1(a)). Noticeably, Act A failed to induce GATA4 in media supplemented with either bFGF or FGF4 (Figure 1(a)).

Worthy to note that at day 5 , no significant upregulation of visceral endoderm and the early hepatogenic marker alpha-fetoprotein (AFP) in cells treated with the studied conditional media, suggesting that Act A and other signaling molecules do not support visceral endoderm lineage differentiation and are not sufficient for hepatogenic specification. Taken together, the increase in expression levels of bonafide DE markers in conditional media supplemented with Act A alone or with Wnt3A suggests that our approaches using chemically defined differentiation conditions have successfully enriched the DE lineage of DPPSCs. Due to the experimental variations in the transcript levels of the $\mathrm{DE}$ genes in cells treated with conditional media supplemented with Act A alone, therefore, the following experiments were carried out using Act A and Wnt3A as the main induction cytokines.

It is well documented that biomaterials in cell cultures support viability, differentiation, maturation, and longterm function $[36,53]$. To further improve the differentiation protocol and study the influence of biomaterials on DPPSC-mediated DE indication, we perused DE differentiation under three different conditions: cells were cultured on plates precoated with collagen I, fibronectin, or cocultured with HepG2 cells for 5 days.

Interestingly, the DE marker gene expression was significantly elevated in DPPSCs differentiated on the scaffolds (Figure 1(b)) versus on no scaffolds (Figure 1(a)). Relative to DPPSCs differentiated on plain plates (Figure 1(a)), FOXA1 transcript levels in cells differentiated on collagen I or fibronectin were 3- to 4-fold higher, respectively. Similarly, the expression levels of FOXA2 mRNA were elevated by 1.5 - to 3 -fold when cells were differentiated on the scaffolds (Figure 1(b)). qRT-PCR analyses of GATA4 transcripts were significantly enriched in cells differentiated with collagen I or fibronectin, 120-fold increase relative to undifferentiation cells, at day 5 (Figure 1(b)). No DE marker gene expressions were detected in DPPSCs cocultured with HepG2, suggesting a differentiation suppression effect of hepatic cells (Figure 1(b)). Furthermore, the used biomaterials did not facilitate prospective generation of visceral endoderm cells and did not support early hepatogenic specification, since AFP transcripts were not detected. In summary, biomaterial usage enhanced DPPSC-mediated DE differentiation. Since collagen I is an affordable, inexpensive substrate, and commonly used in stem cell studies, we use it as the scaffold to induce hepatogenic differentiation.

3.2. Hepatic Specification and Maturation. We investigated the developmental progress in the hepatogenic differentiation potential of DPPSCs using a two-step protocol, which is schematically illustrated and presented in Figure 2. At day 5 after DE induction, the conditional media were supplemented with FGF4 and HGF, for 8 days, to enrich for hepatic cell specification, followed by an 8-day culture in HCM supplemented with hepatogenic inducers such as OSM and Dex in addition to the growth factors (Figure 2).

As we have previously reported, DPPSCs grow as a flat monolayer and exhibit a small spindle-shaped fibroblastlike morphology when cultured on polystyrene tissue culture plates or scaffolds (Figure 3(a)) [25]. During the differentiation induction period, DPPSC morphology further changed to a round or epithelioid shape, a characteristic of $\mathrm{DE}$ cells (Figure 3(b)) [54]. At day 7, the cells became flat and tightly packed, and by day 22 , they adopted a hepatocyte-like morphology (Figures 3(c)-3(e)). In contrast, undifferentiated cells cultured in regular growth medium containing FBS leaned toward an elongated spindle-shaped fibroblastic morphology (Figure 3(f)).

At the molecular level, gene expression studies revealed a distinct early posterior foregut signature at day 7 of DPPSC differentiation. The transcript levels of hepatic nuclear factor 6 (HNF6) and cytokeratin 19 (CK19) were notably elevated at day 7 , relative to undifferentiated cells (Figure 4), indicating a significant commitment toward the foregut tube. Although the transcripts of GATA4 were 


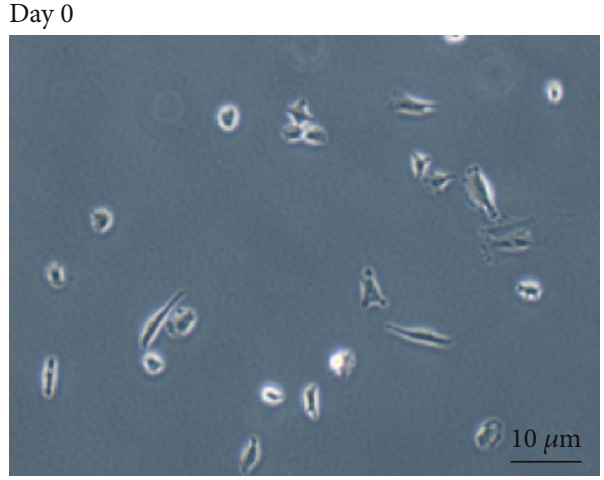

(a)

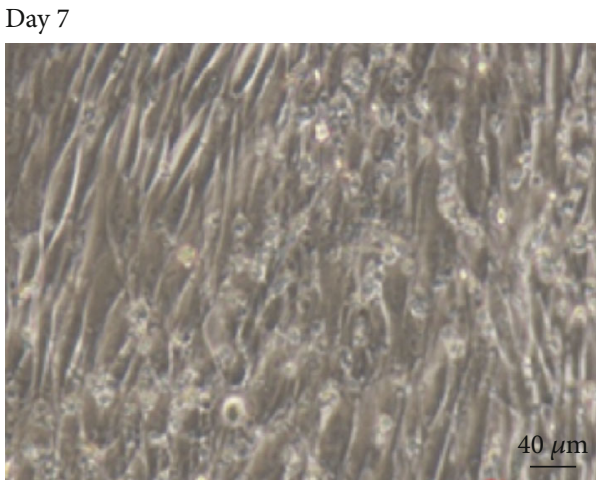

(c)

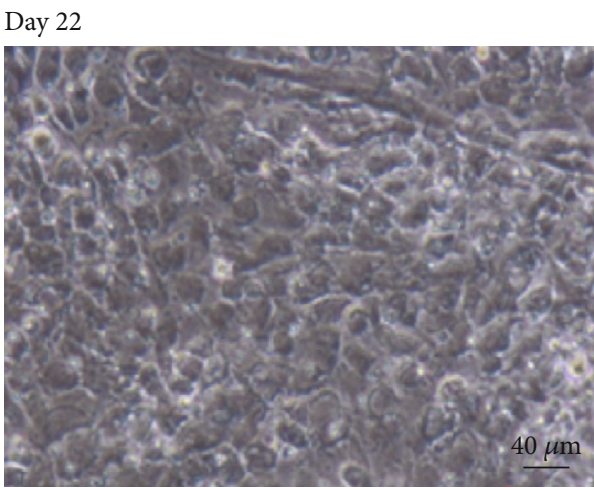

(e)

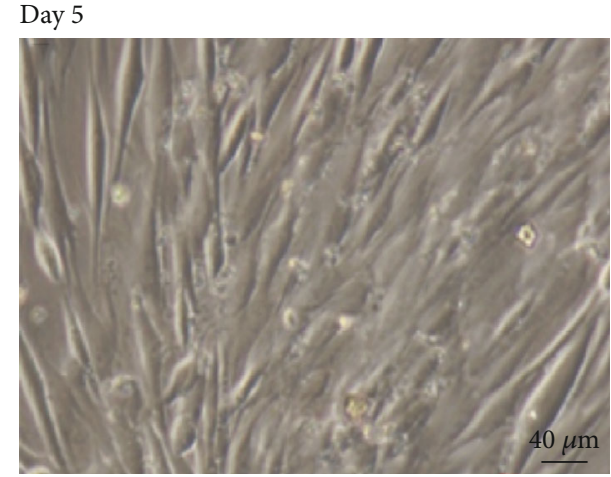

(b)

Day 15

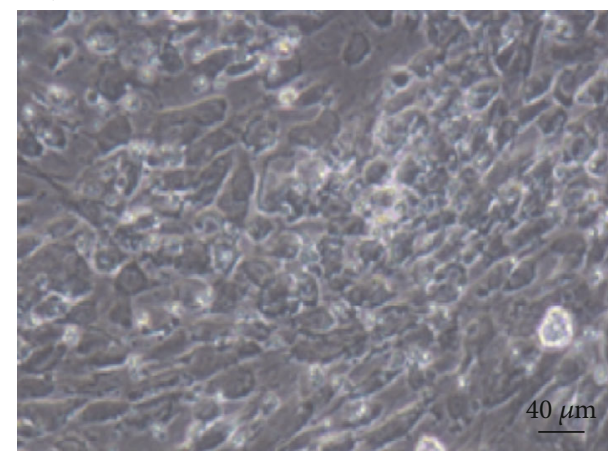

(d)

Day 22 undifferentiated

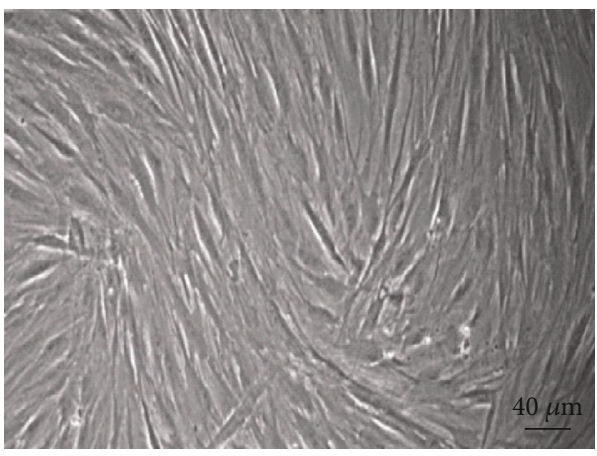

(f)

FIGURE 3: Changes of cellular morphological during the time course of DPPSC-mediated hepatocyte-like cells. Phase-contrast representative images of DPPSCs at different stages of differentiation from day 0 to day 22 and undifferentiated cells at day 22. Scale: (a) 100x magnification and (b-f) 200x magnification.

upregulated at day 5 (Figure 1(b)), simultaneously with the DE markers, its elevated expression levels were maintained until day 7 unlike FoxA1 mRNA levels which were significantly reduced at day 7 . This observation is likely due to a possible commitment of a small cell fraction to DE lineage and/or a significant profile of these genes in the early posterior foregut (Figure 4) [52, 55].

Next, the developmental progress of differentiated DPPSCs toward hepatogenic specification was investigated at day 14 of treatment with conditional media. A notable reduction in the expression levels of the foregut tube markers was observed, concomitant with a significant increase in AFP transcripts (Figure 4), which was not observed in earlier stages of differentiation, indicating a progression toward early hepatic specification. In addition, moderate levels of hepatic markers' transcripts were noticed at day 14 (Figure 4), including hepatic nuclear factor $4 \alpha$ (HNF4 $\alpha$ ), glucose 6-phosphate (G6P), and cholesterol 7 alpha-hydroxylase (CYP7A1). The induction of hepatogenic markers inspired us investigate the differentiation efficiency using flow cytometry. The differentiation protocol resulted in a notable enrichment of prehepatocyte-like cells with 

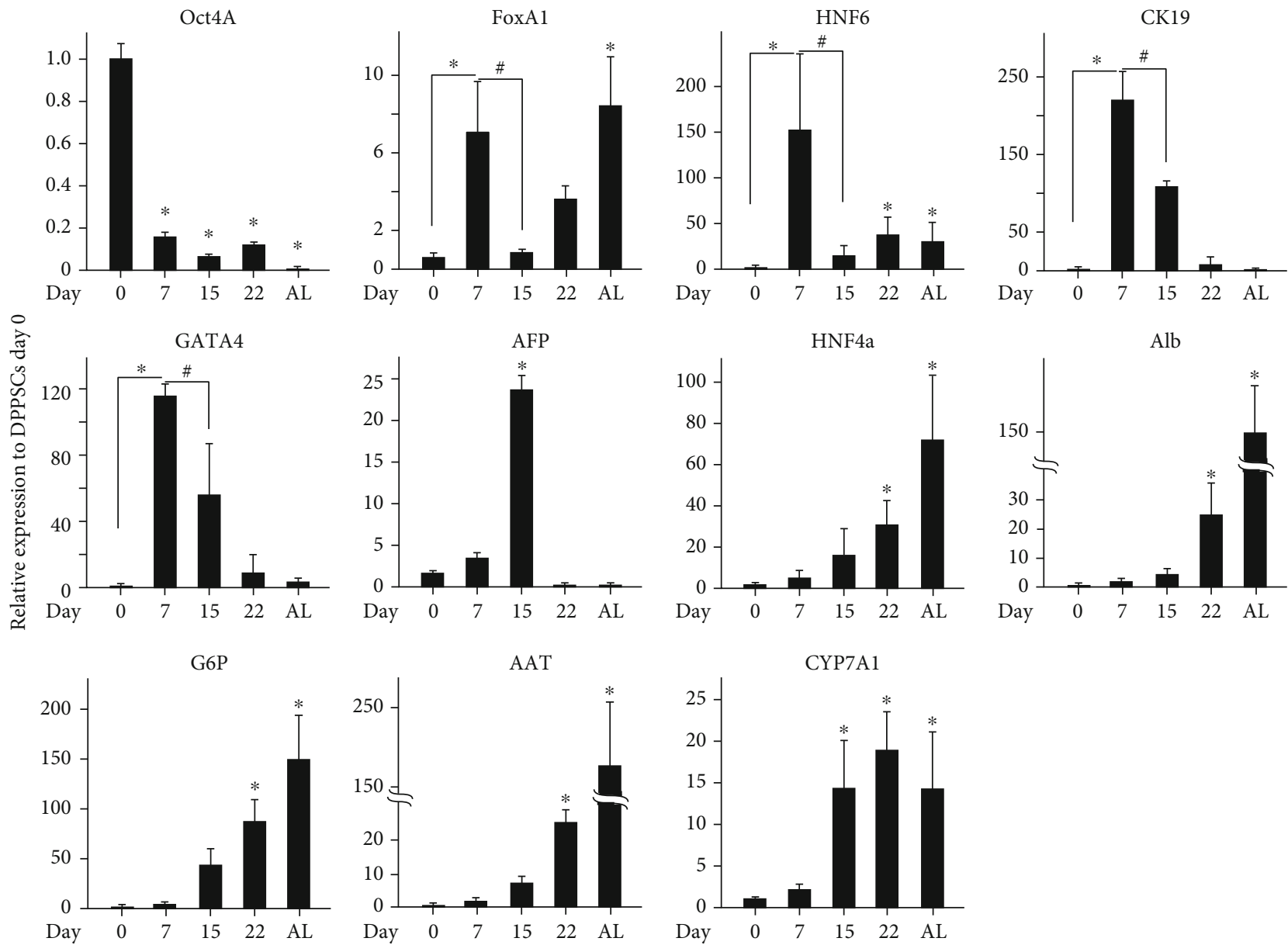

FIgURE 4: Molecular and cellular evaluation of DPPSC-mediated hepatocyte-like cells. Time course qRT-PCR analysis for lineage-specific gene expression. The differentiation was performed using the previously described experimental protocol. Total RNA was harvested from the cells at the indicated days for gene expression. Results were normalized to GAPDH and expressed relatively to DPPSCs at day $0 .{ }^{*} p<0.05$ and ${ }^{\#} p<0.05$ relative to day 7 . Data are shown as the mean \pm SD $(n=4)$.

$44 \%$ of the total cell counts which were positive to AFP proteins at differentiation day 14 (Supplementary Figures 1C and 1D).

Simultaneously, an eight-day treatment of these committed DPSSCs with HCM supplemented hepatic induction molecules resulted in a significantly exaggeration in the expression levels of the hepatic markers at differentiation day 22. Relative to undifferentiated DPPSCs, the HNF4 $\alpha$ and Alb transcripts were 40-and 15-fold higher, AAT and CYP7A1 transcripts were 20-fold higher, and G6P mRNA levels were 100-fold higher at day 22 (Figure 4). Taken together, we implemented an optimized a 3-stage protocol that directed a stepwise differentiation of DPPSCs to the hepatocyte-like cell populations.

\subsection{DPPSC-Derived Hepatocyte-Like Cells Demonstrate} Hepatic Function. Next, to corroborate the qRT-PCR analysis and evaluate the differentiation efficiency, we ascertained the protein expression of the hepatogenic markers by immunolocalization and functional analysis. Immunofluorescence with specific antibodies directed against AAT and Alb proteins revealed a significant expression of these hepatic markers at day 22 of DPPSC differentiation (Figures 5(a) and 5(b)).

Mature hepatocytes are characterized by their ability to store glycogen [56]. Interestingly, most of the differentiated DPPSCs showed a significant positive periodic acid-Schiff (PAS) staining in the cytoplasm, albeit to a different degree, at day 22 (Figure 5(c) and Supplementary Figure 2), which is indicative for glycogen storage, and the generation of mature hepatocyte-like cells. Alternatively, no PAS staining was detected in undifferentiated cells (Figure 5(d)).

Then, we investigated the activity of hepatic metabolic enzymes. Time course studies performed on protein extracts from differentiated DPPSCs for GGT, AST, ALP, and ALT activities revealed a time-dependent upregulation of liver metabolic enzymes which beaked at day 18 of differentiation (Figures 6(a)-6(d), respectively). Furthermore, the enzymatic activity of CYP3A4 was significantly induced in differentiated DPPSCs after treatment with rifampicin, 5fold relative to untreated cells. Cotreatment with erythromycin, a CYP3A4 inhibitor, significantly downregulated the observed enzymatic action against rifampicin (Figure 6(e)). 

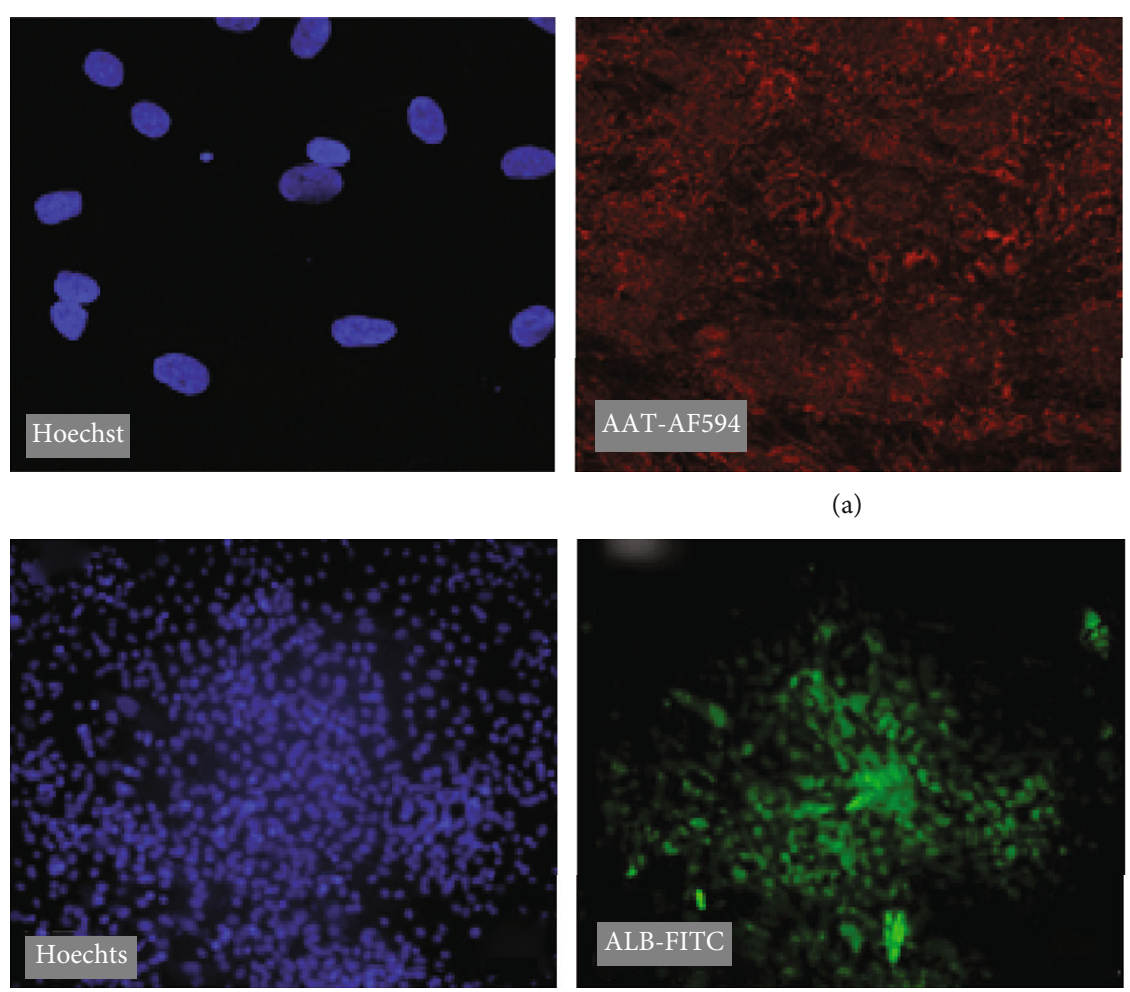

(a)

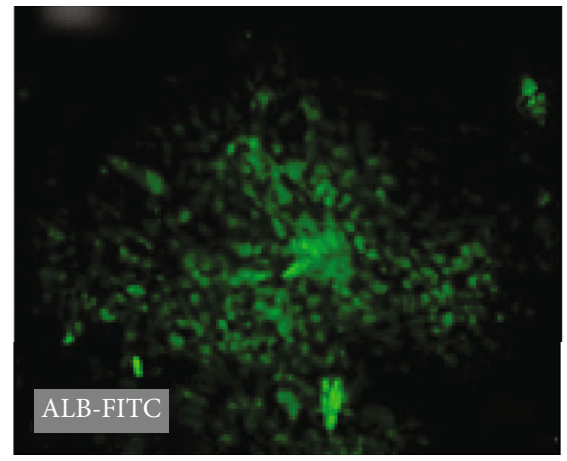

(b)

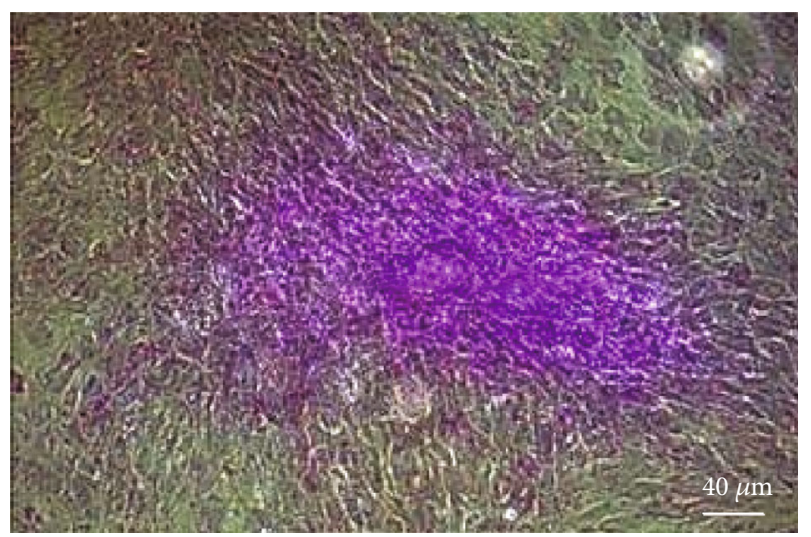

(c)
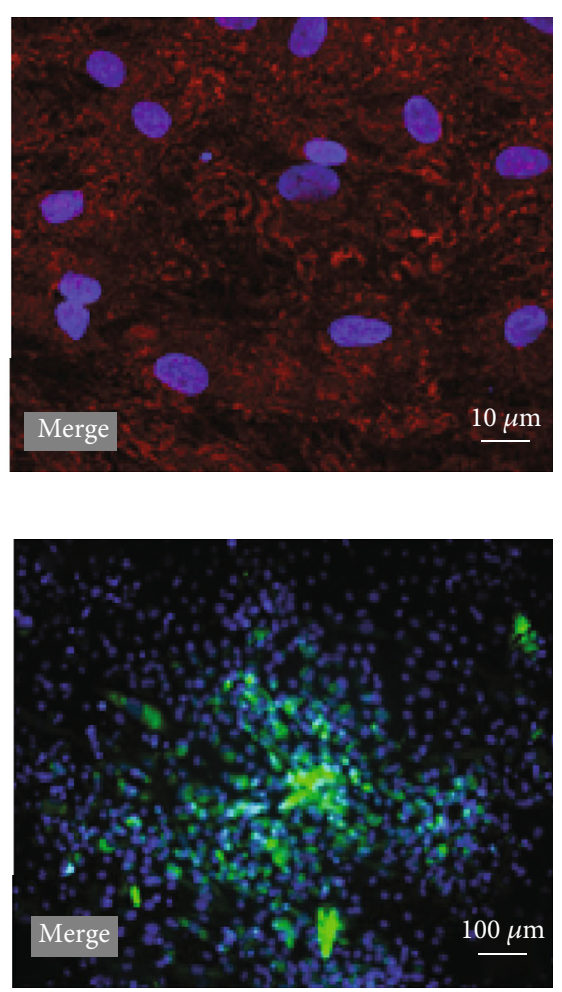

$\mu \mathrm{m}$

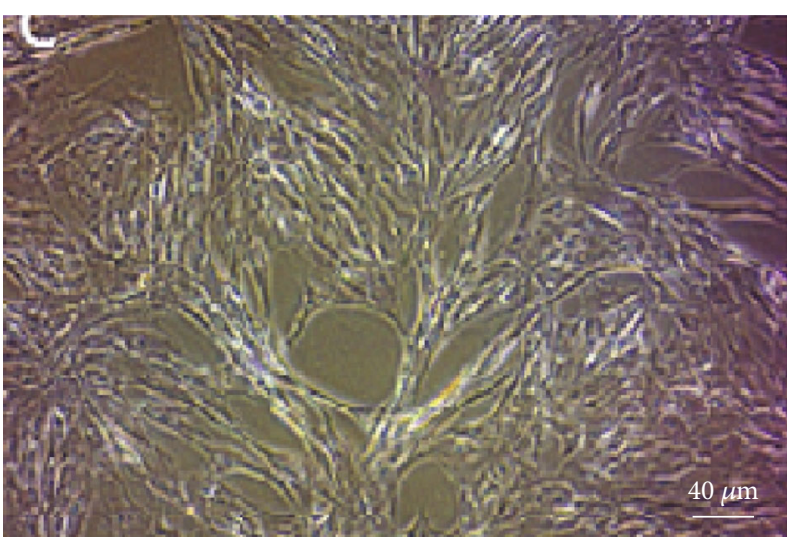

(d)

FiguRE 5: Protein expression and glycogen storage of DPPSC-mediated hepatocyte-like cells. (a, b) Representative fluorescence microscopy images of DPPSC-mediated hepatocyte-like cells at day 22, immunoassayed with antibodies directed against (a) AAT (AF594, red) and (b) ALB (FITC, green) proteins. Hoechst nuclear marker in blue. 200x magnification. (c, d) Representative light microscope images of differentiated and undifferentiated DPPSCs at day 22, respectively, stained with periodic acid-Schiff (PAS) for glycogen storage detection. 100x magnification.

Alb secretion was assayed at the time course of the differentiation process. As shown in Figure 6(f), at earlier stages of hepatogenesis, day 16 of differentiation, a limited amount of secreted Alb was detected in the media. However, at differentiation days 19 and 22, the amount of secreted albumin was triplicated into $3.5 \mu \mathrm{g} / \mathrm{mg}$ protein (Figure 6(f)). Taking these observations together, the described differentiation protocol (Figure 2) efficiently induced the generation of DPPSC-mediated functional hepatocyte-like cells and indicates that DPPSCs are a useful cell model for hepatogenesis.

\section{Discussion}

The current strategy in stem cell differentiation protocols is to mimic cellular signaling events associated with the embryonic developmental process for the lineage of interest [8, 47, 48]. However, in vitro cell differentiation gives a broad range of outcome lineages; thus, the development of a protocol that significantly improves a targeted cell type is of particular interest [49]. Targeted differentiation requires culturing the cells in chemically well-defined media, which regulate cell 


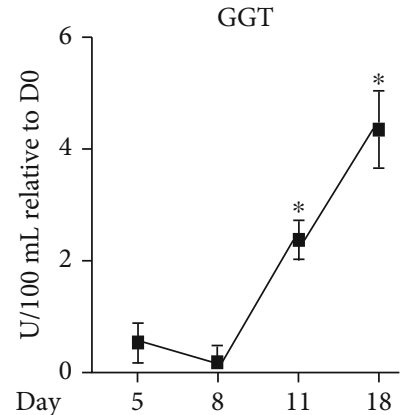

(a)

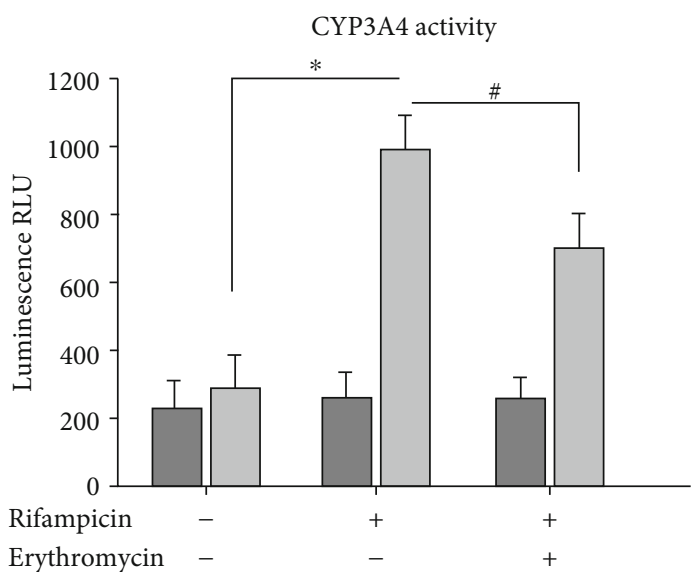

(e)

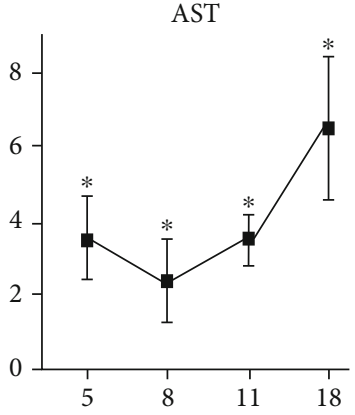

(b)

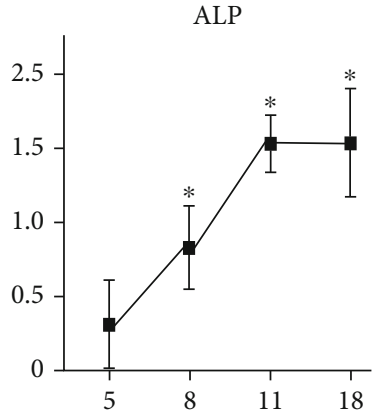

(c)

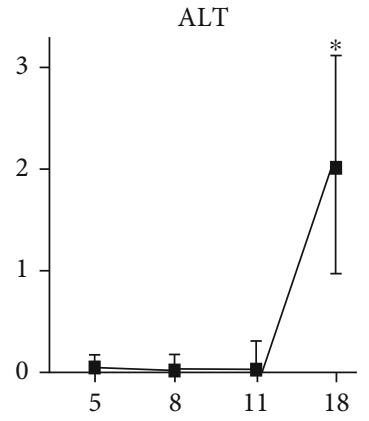

(d)

Alb secretion

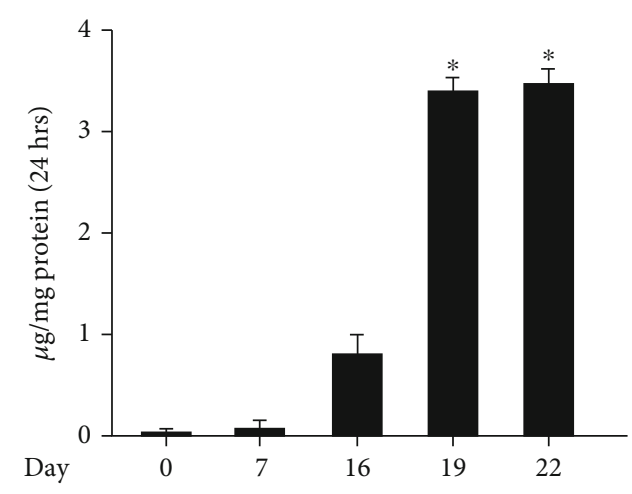

(f)

$\square$ D0

$\square \mathrm{D} 22$

FIGURE 6: Functional analysis of the generated DPPSC-mediated hepatocyte-like cells. Time course hepatocyte enzymatic activities of (a) GGT, (b) AST, (c) APF, and (d) ALT were performed for the differentiated DPPSCs. A notable induction was observed at day 18. (e) CYP3A4 activity was measured by luminescence in DPPSCs at day 0 and day 22 of differentiation using rifampicin in the presence or absence of the antagonist erythromycin. (f) Alb secretion assay was performed at a time course differentiated DPPSCs; elevated level of secreted Alb was detected at day 19 and later. All measurements are relative to DPPSCs at day $0 .{ }^{*} p<0.05$ and ${ }^{\#} p<0.05$ relative to rifampicin treatment alone. Data are shown as the mean $\pm \mathrm{SD}(n=4)$.

signaling pathways, resulting in the generation of cell type of interest. This approach has been successfully applied to hESCs and iPSCs [51-53], but has yet to be applied to other pluripotent cell types, including adult DPPSCs.

In this study, we applied an optimized 3D and 3-stage protocol directed toward a stepwise differentiation of DPPSCs to hepatocyte-like cells. For efficient differentiation, cells were checked at each developmental stage using lineagespecific markers. Initially, DPPSCs were cultured for 5 days in differentiation media supplemented with Act A, with or without Wnt3a, BMP4, or the growth factors bFGF and FGF4. Interestingly, Act A alone was sufficient to induce $\mathrm{DE}$ differentiation. Our results are in accordance with the reported role of Act A inducing DE from pluripotent stem cells $[55,57]$. It is well known that nodal signaling is required for endoderm specification during the gastrulation [58]. Furthermore, DE induction depends on the duration of exposure to the stimulation factors. Agarwal et al. reported that 5-day incubations are sufficient to induce DE [49].
Media supplemented with Act A and Wnt3A were superior in inducing DE lineage [57, 59]. Using hESCs, Mathew et al. observed an enhanced DE induction using Act A and Wnt3A supplemented media compared to media contained Act A alone [51]. Like hESCs, in this study, we observed an improved induction of DE markers in DPPSCs cultured with Act A and Wnt3A. Alternatively, the growth factors bFGF or FGF4 suppressed Act A-mediated DE induction [60]. Noteworthy, FGF family members are multifunctional factors. They can maintain hESC pluripotency [61] or DE mediator [62], depending on the associated conditions.

During liver development, the BMP signaling is crucial; however, their functional role during in vitro adult stem cell differentiation is not clear. Cultural media supplemented with BMP2 and BMP4 fail to improve hepatogenesis from adipose tissue stem cell [63]. In accordance with the other studies, our results confirmed that the BMP4 signaling has no functional role during DPPSC differentiation into DE reconciled by Act A induction. Otherwise, studies have 
shown that a combination of Act A and the BMP4 signaling induces mesoderm formation [64]. Notably, DE induction was further enhanced using three-dimensional (3D) scaffolds. Treatment with either collagen or fibronectin upregulated DE markers indicated that 3D enhances the cellular programming potential, which is in accordance with previously reported observations using hESCs, iPSCs, and other mesenchymal stem cells $[36,37,65]$.

The use of minimal amount of FBS in differentiation media has been previously reported to inhibit the PI3K signaling [66], which is necessary to enhance Act A-mediated DE generation. Using $0.5 \%$ FBS during the first 5 days of DE induction, D'Amour and her team observed an enhancement in the expression of Sox 17 or FoxA2 in hESCs [57]. In our protocol, we used $0.5 \%$ FBS media for the first 3 days of differentiation. Then, it was replaced with $2 \%$ KOSR for extra 4 days, a serum that has been proven to be effective and suitable with defined components [49]. At differentiation days 722, KOSR was removed and hepatogenic lineage induction was carried on with serum-free conditional culture media. As descripted in the schematic Figure 2, the growth factors FGF4 and HGF were used to induce hepatogenesis, followed by the usage of OSM with Dex for the hepatocytes' maturation. The role of FGF4 and HGF in hepatocyte specification has been previously reported for both Wharton's jelly and bone marrow mesenchymal stem cells [67-69]. In accordance, both FGF4 and HGF were required to mediate hepatic specification in DPPSCs. We observed an improved expression of several hepatic markers including immature and mature markers at day 13 of differentiation.

Studies have shown that the interleukin-6 family cytokine (OSM) is required for hepatocyte maturation in combination with glucocorticoids, such as Dex [70,71]. Additionally, it is well documented that HGF, EGF, and OSM have decisive effects on the maintenance of primary human hepatocytes in vitro [72]. The combination of HGF, OSM, and Dex is widely used in protocols to differentiate stem cells into hepatocytes $[49,73]$. In our protocol, we applied the maturation factors OSM and Dex at day 13 posting commitment to the hepatic fate. Consequently, we documented hepatocyte-like cell maturation using cellular and molecular techniques. After 15 days of exposure to media containing OSM and Dex, we observed changes in cell morphology with hepatocyte-like structures, which was associated with Alb secretion, and the activation of hepatic-specific enzymes.

After the establishment of the most optimal protocol used for DPPSC, we performed the tests that were available for us to prove the efficacy of the differentiation of DPPSC into hepatocyte-like cells. At the molecular level, differentiated DPPSC expressed AAT, Alb, and G6P transcripts, genes that are markers for mature hepatocytes. Moreover, the protein expression of these markers was also documented in our study. Cellular morphological changes were also detected, and mature cells acquired a polygonal shape typical for hepatocytes [74]. In addition, DPPSC-mediated hepatocyte-like cells were functional. These cells stored glycogen, secreted Alb, and other metabolic enzymes as efficient as other stem cell models used for hepatogenesis including MSCs [39] and hESCs [75,
76]. Furthermore, differentiated DPPSCs have shown an improved Cyp3A4 enzymatic activity, suggesting that the generated hepatocyte-like cells can be used as a model for drug metabolism, which would be useful for the pharmaceutical industry [77].

\section{Conclusions}

We designed a novel protocol to differentiate the adult DPPSCs into functional hepatocyte-like cells. Our protocol is a directed differentiation protocol mimicking the stepwise process observed during embryonic liver development. Using DPPSCs as pluripotent-like stem cell models suggests their potential usage for liver regenerative medicine and prospective treatments to be developed in the future. However, for clinical applications, there are still many studies that are needed to be improved, yet the generated functional DPPSC-mediated hepatocyte-like cells can be used as a model for drug screening, hepatic metabolism studies, and hepatic disease applications.

$\begin{array}{ll}\text { Abbreviations } \\ \text { AST: } & \text { Aspartate aminotransferase } \\ \text { BAL: } & \text { Bioartificial liver } \\ \text { CGH: } & \text { Chromosome genomic hybridization } \\ \text { DEX: } & \text { Dexamethasone } \\ \text { DPMSCs: } & \text { Dental pulp mesenchymal stem cells } \\ \text { DPPSCs: } & \text { Dental pulp pluripotent stem cells } \\ \text { EB: } & \text { Embryoid bodies } \\ \text { ECM: } & \text { Extracellular matrix } \\ \text { ESDL: } & \text { End-stage liver disease } \\ \text { GGT: } & \text { Gamma-glutamyl transferase } \\ \text { HB: } & \text { Hepatoblasts } \\ \text { HCC: } & \text { Hepatocellular carcinoma } \\ \text { HT: } & \text { Hepatocyte transplantation } \\ \text { MSC: } & \text { Mesenchymal stromal cells } \\ \text { OLT: } & \text { Orthotopic liver transplantation } \\ \text { OSM: } & \text { Oncostatin M. }\end{array}$

\section{Data Availability}

All data are available upon request.

\section{Disclosure}

A preprint has previously been published [35].

\section{Conflicts of Interest}

The authors declare no conflicts of interest.

\section{Authors' Contributions}

C.G.R. is responsible for the collection and assembly of data and first manuscript draft. S.M. and S.A.D. are responsible for the data analysis and interpretation. M.A.A. and C.M. are responsible for the statistical analysis. E.F.P. and E.F.A are responsible for the provision of study patients and cell isolation. M.B., A.A.M., and M.A. are responsible for the 
conception and design, collection and assembly of data, data analysis and interpretation, manuscript writing, and final approval of the manuscript.

\section{Acknowledgments}

The authors would like to thank Dr. Cámara Vallejo at Oral and Maxillofacial Surgery Department, Hospital Clinico de Barcelona, Barcelona, Spain, for patient's recruitment and molar extractions. This study was funded by the Universitat Internacional de Catalunya (UIC), the Agència de Gestió d'Ajuts Universitaris i de Recerca, Generalitat de Catalunya project number (SGR 1060 for MA), the Kuwait Foundation for the Advancement of Sciences (KFAS), and the Dasman Diabetes Institute under project number (RA-2013-009 for AAM). CGR, EMS, and RNT were funded by the predoctoral grant Junior Faculty award from the Obra Social, "la Caixa" Foundation, and UIC.

\section{Supplementary Materials}

Supplementary 1. Supplementary Figure 1: morphological differences between DPSCs and the subpopulation DPPSCs. (A, B) Representative images for DPSC population and isolated DPPSC subpopulation, respectively, showing morphological differences between the two cell populations. (C, D) Representative image for flow cytometry assay showing the expression of GATA4 (green) and AFP (red) markers (yellow color represents cells that overexpress both markers) of DPPSC differentiated to hepatocyte-like cells at day 14 . Hoechst nuclear marker in blue.

Supplementary 2. Supplementary Figure 2: DPPSC-mediated hepatocyte-like cells at differentiation day 22 stained. (A) PAS-unstained cells and (B) PAS-stained cells indicate the ability to store glycogen at this differentiation day. The generated hepatocyte-like cells possess a semipolygonal shape.

\section{References}

[1] A. M. Zorn, Liver Development, StemBook, Cambridge (MA), 2008.

[2] M. Blachier, H. Leleu, M. Peck-Radosavljevic, D. C. Valla, and F. Roudot-Thoraval, "The burden of liver disease in Europe: a review of available epidemiological data," Journal of Hepatology, vol. 58, no. 3, pp. 593-608, 2013.

[3] M. F. Dawwas, A. E. Gimson, J. D. Lewsey, L. P. Copley, and J. H. van der Meulen, "Survival after liver transplantation in the United Kingdom and Ireland compared with the United States," Gut, vol. 56, no. 11, pp. 1606-1613, 2007.

[4] J. Neuberger, "An update on liver transplantation: a critical review," Journal of Autoimmunity, vol. 66, pp. 51-59, 2016.

[5] V. Iansante, R. R. Mitry, C. Filippi, E. Fitzpatrick, and A. Dhawan, "Human hepatocyte transplantation for liver disease: current status and future perspectives," Pediatric Research, vol. 83, no. 1-2, pp. 232-240, 2018.

[6] J. A. Wertheim, H. Petrowsky, S. Saab, J. W. Kupiec-Weglinski, and R. W. Busuttil, "Major challenges limiting liver transplantation in the United States," American Journal of Transplantation : official journal of the American Society of
Transplantation and the American Society of Transplant Surgeons, vol. 11, no. 9, pp. 1773-1784, 2011.

[7] A. Dhawan, R. R. Mitry, and R. D. Hughes, "Hepatocyte transplantation for liver-based metabolic disorders," Journal of Inherited Metabolic Disease, vol. 29, no. 2-3, pp. 431-435, 2006.

[8] F. Wang, L. Zhou, X. Ma et al., "Monitoring of intrasplenic hepatocyte transplantation for acute-on-chronic liver failure: a prospective five-year follow-up study," Transplantation Proceedings, vol. 46, no. 1, pp. 192-198, 2014.

[9] M. Ott and J. V. Castell, "Hepatocyte transplantation, a step forward?," Journal of Hepatology, vol. 70, no. 6, pp. 10491050, 2019.

[10] S. Gronthos, M. Mankani, J. Brahim, P. G. Robey, and S. Shi, "Postnatal human dental pulp stem cells (DPSCs) in vitro and in vivo," Proceedings of the National Academy of Sciences of the United States of America, vol. 97, no. 25, pp. 1362513630, 2000.

[11] F. Ferro, R. Spelat, A. P. Beltrami, D. Cesselli, and F. Curcio, "Isolation and characterization of human dental pulp derived stem cells by using media containing low human serum percentage as clinical grade substitutes for bovine serum," PLoS One, vol. 7, no. 11, article e48945, 2012.

[12] V. Tirino, F. Paino, A. De Rosa, and G. Papaccio, "Identification, isolation, characterization, and banking of human dental pulp stem cells," Methods in Molecular Biology, vol. 879, pp. 443-463, 2012.

[13] W. Zhang, X. F. Walboomers, S. Shi, M. Fan, and J. A. Jansen, "Multilineage differentiation potential of stem cells derived from human dental pulp after cryopreservation," Tissue Engineering, vol. 12, no. 10, pp. 2813-2823, 2006.

[14] N. Pilbauerova, T. Soukup, T. Suchankova Kleplova, J. Schmidt, and J. Suchanek, "The effect of cultivation passaging on the relative telomere length and proliferation capacity of dental pulp stem cells," Biomolecules, vol. 11, 2021.

[15] L. Rambhatla, C. P. Chiu, P. Kundu, Y. Peng, and M. K. Carpenter, "Generation of hepatocyte-like cells from human embryonic stem cells," Cell Transplantation, vol. 12, no. 1, pp. 1-11, 2003.

[16] Y. F. Chen, C. Y. Tseng, H. W. Wang, H. C. Kuo, V. W. Yang, and O. K. Lee, "Rapid generation of mature hepatocyte-like cells from human induced pluripotent stem cells by an efficient three-step protocol," Hepatology, vol. 55, no. 4, pp. 1193-1203, 2012.

[17] K. Si-Tayeb, F. K. Noto, M. Nagaoka et al., "Highly efficient generation of human hepatocyte-like cells from induced pluripotent stem cells," Hepatology, vol. 51, no. 1, pp. 297-305, 2010.

[18] K. D. Lee, T. K. Kuo, J. Whang-Peng et al., "In vitro hepatic differentiation of human mesenchymal stem cells," Hepatology, vol. 40, no. 6, pp. 1275-1284, 2004.

[19] A. Banas, T. Teratani, Y. Yamamoto et al., "Adipose tissuederived mesenchymal stem cells as a source of human hepatocytes," Hepatology, vol. 46, no. 1, pp. 219-228, 2007.

[20] M. J. Seo, S. Y. Suh, Y. C. Bae, and J. S. Jung, "Differentiation of human adipose stromal cells into hepatic lineage in vitro and in vivo," Biochemical and Biophysical Research Communications, vol. 328, no. 1, pp. 258-264, 2005.

[21] N. Ishkitiev, K. Yaegaki, B. Calenic et al., "Deciduous and Permanent Dental Pulp Mesenchymal Cells Acquire Hepatic 
Morphologic and Functional Features_In Vitro_," Journal of Endodontia, vol. 36, no. 3, pp. 469-474, 2010.

[22] N. Ishkitiev, K. Yaegaki, T. Imai et al., "High-purity hepatic lineage differentiated from dental pulp stem cells in serumfree medium," Journal of Endodontics, vol. 38, no. 4, pp. 475480, 2012.

[23] A. Kumar, V. Kumar, V. Rattan, V. Jha, A. Pal, and S. Bhattacharyya, "Molecular spectrum of secretome regulates the relative hepatogenic potential of mesenchymal stem cells from bone marrow and dental tissue," Scientific Reports, vol. 7, no. 1, p. 15015, 2017.

[24] M. Atari, C. Gil-Recio, M. Fabregat et al., "Dental pulp of the third molar: a new source of pluripotent-like stem cells," Journal of Cell Science, vol. 125, Part 14, pp. 3343-3356, 2012.

[25] M. Atari, M. Barajas, F. Hernandez-Alfaro et al., "Isolation of pluripotent stem cells from human third molar dental pulp," Histology and Histopathology, vol. 26, no. 8, pp. 1057-1070, 2011.

[26] M. Atari, J. Caballe-Serrano, C. Gil-Recio et al., "The enhancement of osteogenesis through the use of dental pulp pluripotent stem cells in 3D," Bone, vol. 50, no. 4, pp. 930-941, 2012.

[27] E. Martinez-Sarra, S. Montori, C. Gil-Recio et al., "Human dental pulp pluripotent-like stem cells promote wound healing and muscle regeneration," Stem Cell Research \& Therapy, vol. 8, no. 1, p. 175, 2017.

[28] R. Nunez-Toldra, P. Dosta, S. Montori, V. Ramos, M. Atari, and S. Borros, "Improvement of osteogenesis in dental pulp pluripotent-like stem cells by oligopeptide-modified $\operatorname{poly}(\beta$ amino ester)s," Acta Biomaterialia, vol. 53, pp. 152-164, 2017.

[29] F. Ferro, R. Spelat, F. D'Aurizio et al., "Dental pulp stem cells differentiation reveals new insights in Oct4A dynamics," PLoS One, vol. 7, no. 7, article e41774, 2012.

[30] F. N. Faruqu, S. Zhou, N. Sami, F. Gheidari, H. Lu, and K. T. Al-Jamal, "Three-dimensional culture of dental pulp pluripotent-like stem cells (DPPSCs) enhancesNanogexpression and provides a serum-free condition for exosome isolation," FASEB BioAdvances, vol. 2, no. 7, pp. 419-433, 2020.

[31] R. Nunez-Toldra, E. Martinez-Sarra, C. Gil-Recio et al., "Dental pulp pluripotent-like stem cells (DPPSC), a new stem cell population with chromosomal stability and osteogenic capacity for biomaterials evaluation," BMC Cell Biology, vol. 18, no. 1, p. 21, 2017.

[32] R. V. Nelakanti, N. G. Kooreman, and J. C. Wu, "Teratoma formation: a tool for monitoring pluripotency in stem cell research," Current Protocols in Stem Cell Biology, vol. 32, pp. 4A.8.1-4A.8.17, 2015.

[33] H. Hentze, P. L. Soong, S. T. Wang, B. W. Phillips, T. C. Putti, and N. R. Dunn, "Teratoma formation by human embryonic stem cells: evaluation of essential parameters for future safety studies," Stem Cell Research, vol. 2, no. 3, pp. 198-210, 2009.

[34] K. Zeevaert, M. H. Elsafi Mabrouk, W. Wagner, and R. Goetzke, "Cell mechanics in embryoid bodies," Cells, vol. 9, no. 10, p. 2270, 2020.

[35] C. Gil-Recio, S. Montori, C. Vallejo et al., "Direct differentiation of dental pulp pluripotent-like stem cells differentiation into hepatocyte-like cells," bioRxiv, 2020.

[36] S. Nakai, I. Shibata, T. Shitamichi et al., "Collagen vitrigel promotes hepatocytic differentiation of induced pluripotent stem cells into functional hepatocyte-like cells," Biology open, vol. 8, 2019.
[37] C. H. Rasmussen, D. R. Petersen, J. B. Moeller, M. Hansson, and M. Dufva, "Collagen type I improves the differentiation of human embryonic stem cells towards definitive endoderm," PLoS One, vol. 10, no. 12, article e0145389, 2015.

[38] A. Al Madhoun, S. K. Marafie, D. Haddad et al., "Comparative proteomic analysis identifies EphA2 as a specific cell surface marker for Wharton's jelly-derived mesenchymal stem cells," International journal of molecular sciences, vol. 21, no. 17, p. $6437,2020$.

[39] F. Al-Rashed, S. Sindhu, H. Arefanian et al., "Repetitive intermittent hyperglycemia drives the M1 polarization and inflammatory responses in THP-1 macrophages through the mechanism involving the TLR4-IRF5 pathway," Cell, vol. 9, no. 8, p. 1892, 2020.

[40] A. Al Madhoun, S. Alkandari, H. Ali et al., "Chemically defined conditions mediate an efficient induction of mesodermal lineage from human umbilical cord- and bone marrowmesenchymal stem cells and dental pulp pluripotent-like stem cells," Cellular Reprogramming, vol. 20, no. 1, pp. 9-16, 2018.

[41] A. Khadir, A. Tiss, J. Abubaker et al., "MAP kinase phosphatase DUSP1 is overexpressed in obese humans and modulated by physical exercise," American Journal of Physiology. Endocrinology and Metabolism, vol. 308, no. 1, pp. E71-E83, 2015.

[42] S. Kochumon, A. A. Madhoun, F. Al-Rashed et al., "Adipose tissue gene expression of CXCL10 and CXCL11 modulates inflammatory markers in obesity: implications for metabolic inflammation and insulin resistance," Therapeutic Advances in Endocrinology and Metabolism, vol. 11, article 2042018820930902, 2020.

[43] A. Maher, R. Nunez-Toldra, N. Carrio et al., "The effect of commercially available endodontic cements and biomaterials on osteogenic differentiation of dental pulp pluripotent-like stem cells," Dentistry journal, vol. 6, no. 4, p. 48, 2018.

[44] S. Kochumon, A. Al Madhoun, F. Al-Rashed et al., "Elevated adipose tissue associated IL-2 expression in obesity correlates with metabolic inflammation and insulin resistance," Scientific Reports, vol. 10, no. 1, p. 16364, 2020.

[45] X. W. Wang and B. Seed, "A PCR primer bank for quantitative gene expression analysis," Nucleic acids research, vol. 31, no. 24, pp. 154e-1154, 2003.

[46] J. Ye, G. Coulouris, I. Zaretskaya, I. Cutcutache, S. Rozen, and T. L. Madden, "Primer-BLAST: a tool to design target-specific primers for polymerase chain reaction," BMC Bioinformatics, vol. 13, no. 1, p. 134, 2012.

[47] A. Voronova, E. Coyne, A. Al Madhoun et al., "Hedgehog Signaling Regulates MyoD Expression and Activity," Journal of Biological Chemistry, vol. 288, no. 6, pp. 4389-4404, 2013.

[48] A. Voronova, A. Fischer, T. Ryan, A. Al Madhoun, and I. S. Skerjanc, "Ascl1/Mash1 is a novel target of Gli2 during Gli2induced neurogenesis in P19 EC cells," PLoS One, vol. 6, no. 4, p. e19174, 2011.

[49] S. Agarwal, K. L. Holton, and R. Lanza, "Efficient differentiation of functional hepatocytes from human embryonic stem cells," Stem Cells, vol. 26, no. 5, pp. 1117-1127, 2008.

[50] J. Cai, Y. Zhao, Y. Liu et al., "Directed differentiation of human embryonic stem cells into functional hepatic cells," Hepatology, vol. 45, no. 5, pp. 1229-1239, 2007.

[51] S. Mathew, M. Jaramillo, X. Zhang, L. A. Zhang, A. SotoGutierrez, and I. Banerjee, "Analysis of alternative signaling pathways of endoderm induction of human embryonic stem 
cells identifies context specific differences," BMC Systems Biology, vol. 6, no. 1, p. 154, 2012.

[52] A. Al Madhoun, H. Ali, S. AlKandari et al., "Defined threedimensional culture conditions mediate efficient induction of definitive endoderm lineage from human umbilical cord Wharton's jelly mesenchymal stem cells," Stem Cell Research \& Therapy, vol. 7, no. 1, p. 165, 2016.

[53] T. Takebe, N. Koike, K. Sekine et al., "Engineering of human hepatic tissue with functional vascular networks," Organogenesis, vol. 10, no. 2, pp. 260-267, 2014.

[54] E. L. Calderon-Gierszal and G. S. Prins, "Directed differentiation of human embryonic stem cells into prostate organoids in vitro and its perturbation by low-dose bisphenol A exposure," PLoS One, vol. 10, article e0133238, 2015.

[55] P. Wang, K. D. McKnight, D. J. Wong et al., "A molecular signature for purified definitive endoderm guides differentiation and isolation of endoderm from mouse and human embryonic stem cells," Stem Cells and Development, vol. 21, pp. 22732287, 2012.

[56] C. M. Chinnici, F. Timoneri, G. Amico et al., "Characterization of liver-specific functions of human fetal hepatocytes in culture," Cell Transplantation, vol. 24, pp. 1139-1153, 2015.

[57] K. A. D'Amour, A. D. Agulnick, S. Eliazer, O. G. Kelly, E. Kroon, and E. E. Baetge, "Efficient differentiation of human embryonic stem cells to definitive endoderm," Nature Biotechnology, vol. 23, no. 12, pp. 1534-1541, 2005.

[58] J. G. Robert Lanza, B. Hogan, D. Melton et al., Essentials of Stem Cell Biology, 2009.

[59] S. Toivonen, K. Lundin, D. Balboa et al., "Activin A and Wntdependent specification of human definitive endoderm cells," Experimental Cell Research, vol. 319, pp. 2535-2544, 2013.

[60] R. E. Schwartz, J. L. Linehan, M. S. Painschab, W. S. Hu, C. M. Verfaillie, and D. S. Kaufman, "Defined conditions for development of functional hepatic cells from human embryonic stem cells," Stem Cells and Development, vol. 14, pp. 643655, 2005.

[61] S. Lotz, S. Goderie, N. Tokas et al., "Sustained levels of FGF2 maintain undifferentiated stem cell cultures with biweekly feeding," PLoS One, vol. 8, article e56289, 2013.

[62] N. Shiraki, T. Yoshida, K. Araki et al., "Guided differentiation of embryonic stem cells into Pdx1-expressing regional-specific definitive endoderm," Stem Cells, vol. 26, pp. 874-885, 2008.

[63] A. Bonora-Centelles, R. Jover, V. Mirabet et al., "Sequential hepatogenic transdifferentiation of adipose tissue-derived stem cells: relevance of different extracellular signaling molecules, transcription factors involved, and expression of new key marker genes," Cell Transplantation, vol. 18, pp. 13191340, 2009.

[64] M. A. Laflamme, K. Y. Chen, A. V. Naumova et al., "Cardiomyocytes derived from human embryonic stem cells in pro-survival factors enhance function of infarcted rat hearts," Nature Biotechnology, vol. 25, no. 9, pp. 1015-1024, 2007.

[65] H. Y. Lin, C. C. Tsai, L. L. Chen, S. H. Chiou, Y. J. Wang, and S. C. Hung, "Fibronectin and laminin promote differentiation of human mesenchymal stem cells into insulin producing cells through activating Akt and ERK," Journal of Biomedical Science, vol. 17, p. 56, 2010.

[66] A. B. McLean, K. A. D'Amour, K. L. Jones et al., "Activin A efficiently specifies definitive endoderm from human embryonic stem cells only when phosphatidylinositol 3-kinase signaling is suppressed," Stem Cells, vol. 25, pp. 29-38, 2007.
[67] X. Q. Kang, W. J. Zang, L. J. Bao et al., "Fibroblast growth factor-4 and hepatocyte growth factor induce differentiation of human umbilical cord blood-derived mesenchymal stem cells into hepatocytes," World Journal of Gastroenterology : WJG, vol. 11, no. 47, pp. 7461-7465, 2005.

[68] R. E. Schwartz, M. Reyes, L. Koodie et al., "Multipotent adult progenitor cells from bone marrow differentiate into functional hepatocyte-like cells," The Journal of Clinical Investigation, vol. 109, pp. 1291-1302, 2002.

[69] C. Schmidt, F. Bladt, S. Goedecke et al., "Scatter factor/hepatocyte growth factor is essential for liver development," Nature, vol. 373, pp. 699-702, 1995.

[70] A. Kamiya, T. Kinoshita, and A. Miyajima, "Oncostatin M and hepatocyte growth factor induce hepatic maturation via distinct signaling pathways," FEBS Letters, vol. 492, pp. 90-94, 2001.

[71] S. Hanada, H. Kayano, J. Jiang et al., "Enhanced in vitro maturation of subcultivated fetal human hepatocytes in three dimensional culture using poly-L-lactic acid scaffolds in the presence of oncostatin M," The International Journal of Artificial Organs, vol. 26, pp. 943-951, 2003.

[72] J. Dong, C. F. Mandenius, M. Lubberstedt et al., "Evaluation and optimization of hepatocyte culture media factors by design of experiments (DoE) methodology," Cytotechnology, vol. 57, pp. 251-261, 2008.

[73] X. Li, J. Yuan, W. Li et al., "Direct differentiation of homogeneous human adipose stem cells into functional hepatocytes by mimicking liver embryogenesis," Journal of Cellular Physiology, vol. 229, pp. 801-812, 2014.

[74] P. Godoy, N. J. Hewitt, U. Albrecht et al., "Recent advances in $2 \mathrm{D}$ and $3 \mathrm{D}$ in vitro systems using primary hepatocytes, alternative hepatocyte sources and non-parenchymal liver cells and their use in investigating mechanisms of hepatotoxicity, cell signaling and ADME," Archives of Toxicology, vol. 87, no. 8, pp. 1315-1530, 2013.

[75] R. Ji, N. Zhang, N. You et al., "The differentiation of MSCs into functional hepatocyte-like cells in a liver biomatrix scaffold and their transplantation into liver-fibrotic mice," Biomaterials, vol. 33, pp. 8995-9008, 2012.

[76] K. Subramanian, D. J. Owens, R. Raju et al., "Spheroid culture for enhanced differentiation of human embryonic stem cells to hepatocyte-like cells," Stem Cells and Development, vol. 23, pp. 124-131, 2014.

[77] J. Jozefczuk, A. Prigione, L. Chavez, and J. Adjaye, "Comparative analysis of human embryonic stem cell and induced pluripotent stem cell-derived hepatocyte-like cells reveals current drawbacks and possible strategies for improved differentiation," Stem Cells and Development, vol. 20, pp. 1259-1275, 2011. 